\title{
The kinematics of breast displacement by the treadmill activity levels
}

\author{
Yumi Jang and Jongsuk Chun ${ }^{\dagger}$ \\ Dept. of Clothing \& Textiles, Yonsei University \\ 트레드밀 운동 속도에 따른 유방의 운동학적 변화 연구 \\ 장 유 미·천 종 숙 ${ }^{\dagger}$ \\ 연세대학교 의류환경학과
}

\begin{abstract}
This research sought to analyze the characteristics of breast movement at the treadmill activity levels. It also examined the effect of wearing a sports bra in reducing breast displacement. The subjects for the data collection were females in their $20 \mathrm{~s}(\mathrm{n}=2)$ with $\mathrm{C}$-cup size breast. The experimental conditions were three different moving speeds (4 km/h, jogging: $7 \mathrm{~km} / \mathrm{h}$, and sprinting: $10 \mathrm{~km} / \mathrm{h})$ and two types of sports bras. Three dimensional breast displacement was measured. The displacement of the right nipple point was measured with a 3D motion analyzer. The results show that the breasts were greatly displaced from the walking speed $(4 \mathrm{~km} / \mathrm{h})$ when subjects did not wear any bra. Whereas their breast displacement distance decreased remarkably when they wore sports bras. The nipple point moved $42 \sim 44 \mathrm{~mm}$ in the vertical direction at walking speed with naked condition. But it was reduced by $80 \%$ after wearing sports bras. When subjects running $(7 \mathrm{~km} / \mathrm{h}, 10 \mathrm{~km} / \mathrm{h})$ without any bra, the nipple point moved $122 \sim 141 \mathrm{~mm}$. However it was reduced by $60 \sim 70 \%$ when they wore sports bras. The apartment time (time delay) between at the highest point of the upper body and the nipple was 0.25 seconds at the running speeds ( 7 $\mathrm{km} / \mathrm{h}, 10 \mathrm{~km} / \mathrm{h}$ ) without wearing any bra. After wearing sports bras, the time delay was cut to $0.06 \sim 0.12$ seconds. These results implies that without wearing any bra the skin surrounding the breasts might be seriously pulled at running activity. The functional sports bra suppress breast movement. It might prevent the sagging of breasts by preventing the damage of the Cooper's ligaments.
\end{abstract}

Keywords: running speed(러닝 속도), breast movement(유방 진동), sports bra(스포츠브라)

\section{Introduction}

여성의 유방은 많은 양의 지방조직과 유선 및 콜
라겐으로 구성된 결합조직으로 구성되어 있으며, 지방조직과 결합조직의 조성 비율이 유방의 탄력 성에 영향을 미친다(Rigal et al., 1989). 쿠퍼인대 (Cooper's ligaments)는 인체 조직 중 미세하게 발달

Received 6 March 2014, revised 14 April 2014, accepted 15 April 2014.

본 논문은 석사 학위 청구 논문의 일부임.

${ }^{\dagger}$ Corresponding author (jschun@yonsei.ac.kr)

This is an Open Access article distributed under the terms of the Creative Commons Attribution Non-Commercial License (http://creativecommons.org/licenses/by-nc/3.0) which permits unrestricted non-commercial use, distribution, and reproduction in any medium, provided the original work is properly cited. 
된 섬유조직으로 유방의 무게를 지탱해 주고 형태 를 유지해 주는 기능을 갖는다(Gefen \& Dilmoney, 2007). 선행연구(Cho \& Kim, 2008)는 성인 여성의 유방이 적절하게 지지되지 않은 상태로 방치될 경 우, 일 년 사이 1 $2 \mathrm{~cm}$ 까지 아래로 처질 수도 있다 고 보고하였다.

여성의 유방은 걷거나 뛸 때 전후, 좌우, 상하의 방향으로 진동한다. 일상생활의 많은 동작들은 걷 고 뛰는 동작을 포함하고 있으므로, 일상생활 중에 도 여성들은 유방의 진동을 느낄 수 있다. 특히 지 속적으로 빠른 속도나 높은 강도로 뛰는 운동을 할 때에는 과도한 유방 진동이 발생하여 유방의 통증 을 유발시키기도 한다. 운동 시 나타나는 유방 통 증은 여성들이 운동을 주저하게 만드는 원인이 되 기도 한다(Chang, Gao \& Yan, 2009). 또한 운동 시 발생되는 여성의 유방 진동을 적절하게 예방하지 않으면 유방의 구조적 지지기능을 하는 쿠퍼 인대 의 손상을 가져와, 유방의 하수 현상을 유발할 수 있다(White, Scurr \& Smith, 2009).

선행연구들은 운동 시 나타나는 유방의 진동 크 기는 유방의 크기와 비례하는 경향이 있다고 하였 다. 예를 들어 유방이 큰 여성들은 유방이 작은 여 성들보다 유방의 돌출, 하수, 벌어짐 정도가 크며, 운동 시 유방의 진동 폭과 통증도 크다는 주장도 있 다(Scurr, White \& Hedger, 2011). 따라서 유방이 큰 여성 인구 비율이 높은 미국, 영국, 호주 등에서는 이들을 대상으로 운동 시 발생하는 유방의 진동 방 향과 특성을 계량화 하는 연구를 하였다(Bridgman,

Scurr, White, Hedger \& Galbraith, 2010).

여성 유방의 크기와 형태는 개인이나 인종에 따 라 다르고, 유전적인 요소와 식생활 등의 영향을 받으며, 연령과 수유 경험에 따라 달라진다. 15년 전 이루어진 선행연구(Ko et al., 2000)는 한국 여성 의 유방은 약 $3 \sim 5 \mathrm{~cm}$ 높이로 돌출되어 있으며, 무게 는 약 $150 \sim 200 \mathrm{~g}$ 정도라고 하였다. 그러나 서양 성인 여성의 유방을 연구한 선행연구(Grassley, 2002)는 유방의 평균 무게가 약 $250 \mathrm{~g}$ 정도이며, 유방의 사 이즈가 큰 경우 $325 \sim 500 \mathrm{~g}$ 라고 하였다. 최근 우리 나라 여성들의 체형도 서구화 되어감에 따라 큰 사 이즈 유방의 출현 빈도가 증가하는 경향을 보이며, $\mathrm{B}$ 컵과 $\mathrm{C}$ 컵 사이즈 브라에 대한 수요가 증가하고
있다(Ko, 2013). 따라서 한국 여성들을 대상으로 한 유방의 운동 역학적 연구가 필요하며, 특히 유방의 사이즈가 큰 한국 여성을 대상으로 유방 진동 특성 에 대한 계량적 연구가 필요함을 시사한다. 이러한 연구는 운동 시 발생하는 과도한 유방의 진동을 예 방할 수 있는 구체적인 방안을 모색하는 기초자료 로 유용하게 사용할 수 있다. 그러나 이 분야의 연 구는 아직 활발하게 이루어지지 않고 있다.

\section{Literature Review}

유방의 형태를 유지해 주고 유방을 흥벽에 부 착시키는 역할을 하는 쿠퍼 인대는 인체에서 가장 약한 인대에 속하며, 유방이 반복적으로 과도하게 진동되면 손상될 수 있다. 그러나 쿠퍼 인대의 역 학적 특성에 대한 구체적인 측정 데이터는 보고된 바가 거의 없으며, 유방의 쿠퍼 인대와 가장 유사 할 것이라고 예상되는 무릎의 현수인대(Suspensory ligaments)를 기준으로 쿠퍼 인대의 역학적 특성 을 파악하였다. 선행연구에 의하면 쿠퍼인대의 탄 성계수는 80 400MPa이며, 인장강도는 $40 \mathrm{MPa}$ 라고 추정된다(Woo, Ambramouwitch, Kilger \& Lianf, 2003). 유방의 무게를 지탱하는 역할을 하는 쿠퍼 인대 는 한번 손상되면 원상태로 회복되지 못하므로, 손상될 경우 유방이 늘어지거나, 처진 형태로 변 형되는 원인이 된다(Starr, 2005). 이러한 유방 변 형의 문제를 해결하기 위해서는 운동 시 유방의 진동을 감소시켜 주는 기능을 가진 브라를 착용 하여 쿠퍼 인대의 손상을 방지하여야 한다(Kim, 2008).

운동 시 여성의 유방이 과도하게 진동하는 현상 을 억제시키는 방안을 찾기 위해서는 유방 진동의 운동역학적 특징을 과학적으로 입증하는 것이 필 요하다. 유방의 진동 변위 특징을 운동역학적 관점 에서 구체적으로 파악한 선행연구(Scurr, White \& Hedger, 2010)는 운동 시 여성의 유방은 전후, 좌우, 상하로 입체적인 궤적을 그리면서 진동하며, 유방 이 큰 경우, 진동 폭이 더 커지는 경향을 나타낸다 고 하였다. 유방의 진동 특성을 세밀하게 측정하는 방법으로 선행연구는 3 차원 동작분석기를 이용하 여 유방의 진동 폭과 범위를 측정하였다(Haake \& 
Scurr, 2010). 이들은 운동 시 유방의 위치 변화를 파악하기 위해 유두점에 랜드 마크를 부착하여 좌 표 값을 측정하였다. 유방은 흥곽에 부착된 상태로 상체의 일부로 움직이므로 순수한 유방의 진동 특 성을 파악하기 위해서 몸 전체의 위치 값을 유방의 위치 값에서 보정하였다. 흥곽의 위치를 파악하기 위하여 앞목점 및 좌우 10 번째 갈비뼈의 하단 끝점 에 랜드마크를 부착하여 랜드마크의 좌표값을 측 정하였다. 이 연구는 유방 사이즈가 $\mathrm{C}$ 컵에 해당하 는 여성의 유방 진동 파형을 분석한 결과, 브라를 착용하지 않은 상태로 $10 \mathrm{~km} / \mathrm{h}$ 의 속도로 러닝하면 유두점이 상하 방향으로 80 120mm 진동한다고 주 장하였다. 그러나 좌우 유방을 각각 감싸는 형태인 인캡슐레이션 스타일 스포츠브라를 착용했을 때에 는 유두점의 진폭이 $12 \mathrm{~mm}$ 로 현저하게 감소한다고 하였다. 그러나 이 연구의 결과는 단 한 명의 피험 자를 대상으로 실시한 실험 결과이므로 결과의 일 반화에 주의가 필요하다.

걷거나 뛰는 동작의 운동을 할 때 나타나는 유방 의 충격에 대한 분석은 유방의 생체학적인 이해를 바탕으로 이루어질 수 있으며, 이는 여성의 유방을 아름답게 유지할 수 있도록 하는 방안을 연구하는데 중요한 자료로 사용될 수 있다(Gefen \& Dilmoney, 2007). 또한 여성 유방에 대한 운동 역학적 분석 자 료들은 인체공학적인 스포츠브라 설계를 위한 핵 심적인 기술이라고 할 수 있다(Chang et al., 2009;

Page \& Steele, 1999).

따라서 본 연구에서는 여성 유방에 대한 운동 역학적 특성을 파악하기 위하여 운동 속도에 따른 유방의 진동 특성과 스포츠브라 착용이 유방 진동 감소에 미치는 효과를 정량적으로 파악하고자 하 였다.

\section{Methods}

\section{Subjects}

본 연구는 최근 한국 여성인구 중 유방 사이즈가 큰 여성의 비율이 증가함을 반영하여 유방이 큰 여 성을 대상으로 유방 진동 파형데이터를 수집하고 분석하였다. 실험대상자는 쿠퍼 인대의 손상이 크 지 않은 20 대 미혼 여성으로 제한하여 모집하였다. $\langle$ Table 1〉 Body measurement of the subjects

\begin{tabular}{c|c|c|c|c|c}
\hline Subject & $\begin{array}{c}\text { Bust } \\
(\mathrm{cm})\end{array}$ & $\begin{array}{c}\text { Under } \\
\text { bust }(\mathrm{cm})\end{array}$ & $\begin{array}{c}\text { Cup size } \\
(\mathrm{cm})\end{array}$ & $\begin{array}{c}\text { Height } \\
(\mathrm{cm})\end{array}$ & $\begin{array}{c}\text { Weight } \\
(\mathrm{kg})\end{array}$ \\
\hline 1 & 91.0 & 75.5 & 15.5 & 160.2 & 58.6 \\
\hline 2 & 91.2 & 75.0 & 16.2 & 158.2 & 66.4 \\
\hline
\end{tabular}

Note: Cup size=Bust G. - Under bust G.

피험자들은 출산과 수유 및 유방 성형 경험이 없는 조건을 만족시키며, 한국 산업규격 파운데이션 의 류치수(KS K 9404: 2009)에서 제시한 브라 사이즈 $75 \mathrm{C}$ 에 해당하는 여성 $(\mathrm{n}=2)$ 이었다. 피험자 1 의 나이 는 28 세, 키는 $160.2 \mathrm{~cm}$, 체중은 $58.6 \mathrm{~kg}$ 이었으며, 피 험자 2 의 나이는 25 세, 키는 $158.2 \mathrm{~cm}$, 체중은 $66.4 \mathrm{~kg}$ 이었다(Table 1). 브라 컵 사이즈를 판정하는 기준인 젖가슴둘레(Bust G.)와 젖가슴아래둘레(Under bust G.)의 차이는 각각 $15.5 \mathrm{~cm}$ 와 $16.2 \mathrm{~cm}$ 로 한국산 업표준규격(KS K 9404: 2009)에서 제시하는 브라 컵 사이즈 판별 기준 중 $\mathrm{C}$ 컵 $(15 \pm 2.5 \mathrm{~cm})$ 의 범위 안 에 포함되었다. 실험 대상자들은 연구 목적과 실험 방법에 대한 설명을 듣고, 실험 참여 동의를 한 후 실험에 참가하였다.

\section{Experimental garments}

스포츠브라의 형태는 일반적으로 브라 컵 요소 유무에 따라 콤프레션(compression) 스타일과 인캡 슐레이션(encapsulation) 스타일로 나뉜다. 실험복은 선행연구(Jang \& Chun, 2013)의 검증 결과에 따라 주관적 착용감이 비슷하게 우수한 콤프레션 스타일 스포츠브라(RCasall style \#1620)와 인캡슐레이션 스타일 스포츠브라(RPurelime style \#098)로 선정 하였다(Fig. 1). 두 스타일 모두 앞중심과 옆중심의 높이가 높았다. 각각의 특징을 살펴보면, 콤프레션 스타일 스포츠브라(Fig. 1(a)) 는 브라 컵 요소는 없으나, 전면에 프린세스 라인이 있어 유방의 입체 적인 모양이 유지될 수 있도록 구성되어 있었다. 후 면은 어깨끈이 등 중앙으로 모이는 레이서백(racer back) 스타일이었다. 소재와 형태는 겉감과 안감이 동일하였다. $45 \%$ polyamide tactel micro, $41 \%$ polyamide, $14 \%$ elasthane를 사용하였다. 인캡슐레이션 스타일 스포츠브라(Fig. 1(b))는 좌우 유방을 분리 하여 커버하는 브라 컵의 형태가 포함되어 있었으 


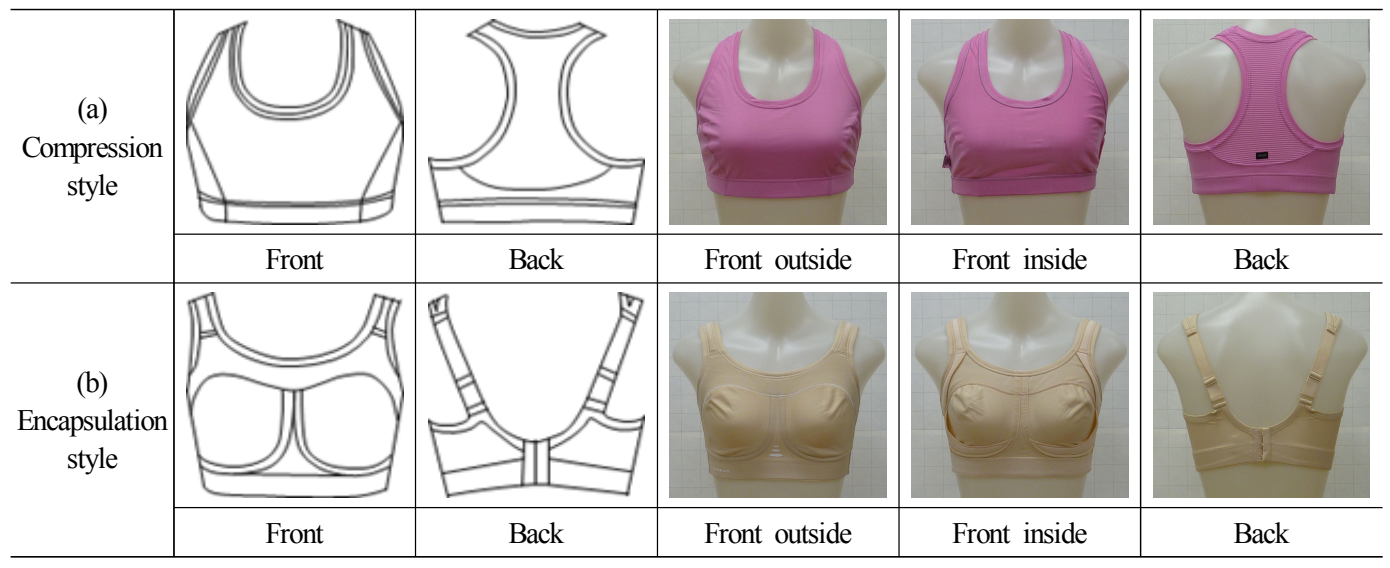

〈Fig. 1〉 Experimental sports bras

며, 브라 컵 상단에 윗 가슴을 가로로 감싸는 띠 형 태의 상단 지지대가 있는 형태이었다. 러닝 시 충 격을 감소시키기 위해 브라 컵 내부와 어깨끈에 패 드가 삽입되어 있었으며, 어깨끈은 길이 조절이 가 능한 구조였다. 후면은 낮은 U자 형태이었으며, 뒤 여밈 장치가 있는 스타일이었다. 소재는 $100 \%$ Polyester이었다.

\section{Data collection}

유방의 진동 파형 데이터는 Haake and Scurr(2010) 가 제안한 방법을 적용하여 수집하였다. 데이터 수 집 장비는 8 대의 적외선 카메라로 구성된 $3 \mathrm{D}$ 동작 분석기(VICON Motion Capture Systems, Ltd, Oxford, $\mathrm{UK}$ )였다. 실험 대상자들은 브라를 착용하지 않은 상태와 2종의 실험용 스포츠브라를 각각 착용한 상 태의 총 3 가지 실험 의류 조건으로 각각 러닝머신 위에서 워킹 $(4 \mathrm{~km} / \mathrm{h})$ 과 조깅 $(7 \mathrm{~km} / \mathrm{h})$ 및 스프린팅 $(10 \mathrm{~km} / \mathrm{h})$ 의 3 가지 속도로 3 분씩 운동하는 상태에서 각 속도의 후반 30 초에서 유방의 진동 데이터를 수 집하였다.

유방 진동 데이터는 측정점의 $\mathrm{X}$ (anterior/posterior), $\mathrm{Y}$ (medial/lateral), Z(superior/inferior) 좌표값으로 수 집하였다. 측정 기준점은 좌우 유두점(right nipple) (1),2), 앞목점(3): suprasternal notch), 10 번째 갈비뼈 좌 - 우(4),(5))의 하단 끝점(left and right anterior inferior $10^{\text {th }}$ ribs)에 지름이 $14 \mathrm{~mm}$ 반구형의 반사 마 커를 부착하였다(Fig. 2).

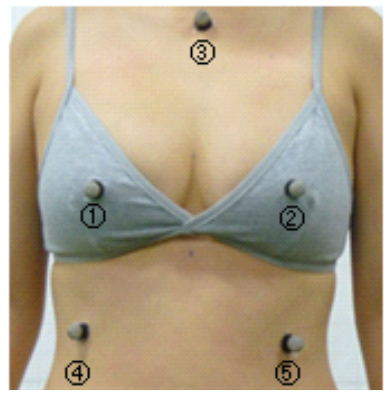

〈Fig. 2〉 Marker points

\section{Data analysis}

유방의 진동 특성은 유두점과 앞목점의 진동 파 형 데이터를 비교 분석하였다. 유방은 전후(X), 좌 우(Y), 상하(Z) 방향에서 진동하였다. 〈Fig. 3〉은 앞 목점 진동 파형(점선)과 유두점의 진동 파형(실선) 을 나타내었다. 유두점의 진동 파형은 유두점 좌표 값에서 앞목점 좌표 값을 상쇄하여 산출하였다. 이 는 추출한 유두점 좌표 값에는 몸 전체의 위치 변화 값이 포함되어 있으므로, 이를 제거하여 순수한 유 두점의 진동 데이터를 수집하기 위함이었다.

유두점의 진동 범위는 Vicon Nexus 1.7(UK) 소 프트웨어로 분석하였다. 각각의 랜드마크 좌표값은 설정된 속도의 운동을 시작한 후 2 분 30 초가 지난 시점부터 30 초 동안 수집하였고, 이 중 중간에 위 치한 5 회의 보행 주기(gait cycle) 구간을 대상으로 
분석하였다. 각 방향의 진동 파형을 살펴보면 최고 점과 최저점을 나타내는 변곡점(point of inflection) 이 전후와 좌우 방향에서는 각 보행 주기에서 1회 발생하였으나, 상하 방향에서는 2회씩 최고점과 최 저점의 변곡점이 발생하였다. 상하 방향 진동 파형 은 총 19 개 변곡점이 발생하였으며, 이중 초기와 후기 변곡점을 제외한 17 개 변곡점의 좌표값을 분 석하여 진폭 데이터를 추출하였다.

운동 시 유방 피부에서 느껴지는 통증은 앞목점 과 유두점 진동의 방향이 어긋남에 원인이 있다 (Haake \& Scurr, 2010). 따라서 본 연구에서는 앞목 점과 유두점 진동의 방향이 어긋남 현상을 파악하 기 위하여 앞목점 진동 파형과 유두점 진동 파형의 변곡점 발생 시간 차이(time delay)를 측정하였다. 앞목점 진동 파형과 유두점 진동 파형에 나타난 각 각 9 회의 변곡점 발생 시간을 측정하여 비교하였 다. 앞목점과 유두점의 진동 파형의 진행 시간 특 성을 비교한 그래프는 조깅 $(7 \mathrm{~km} / \mathrm{h})$ 과 스프린팅 $(10 \mathrm{~km} / \mathrm{h})$ 속도에서 측정한 상하 방향(Z, Vertical) 진동 파형 그래프였다.

\section{Results and Discussion}

\section{Breast vibration at the bra condition}

운동 시 여성의 유방 진동 특성은 브라를 착용하 지 않은 상태에서의 유두점 진동 파형을 분석하였 다. 워킹 $(4 \mathrm{~km} / \mathrm{h})$ 과 조깅 $(7 \mathrm{~km} / \mathrm{h})$ 및 스프린팅 $(10 \mathrm{~km} /$ h) 속도에서의 유방 진동 특성을 분석한 결과, 조깅 $(7 \mathrm{~km} / \mathrm{h})$ 할 때부터 좌우(Y)와 상하 $(\mathrm{Z})$ 방향으로 유 방이 크게 진동하였고, 상하 방향은 전후 $(\mathrm{X})$ 와 좌 우(Y) 방향에 비해 2배의 진동 주기를 나타냈다.

유두점과 앞목점의 진동 파형의 최고점 발생 시 점은 일치하지 않았다. 상하(Z) 방향 진동은 앞목점 이 최저점일 때 유두점은 최고점을 나타내는 경향 을 보였다(Fig. 3). 즉 몸이 위로 뛰어 오를 때 유두 점은 도리어 하강하는 경향을 나타내었다. 좌우(Y) 방향 진동도 유두점과 앞목점의 진동 파형이 반대 로 움직이는 경향을 나타내었다. 이러한 진동 파형 의 불일치는 러닝 시 유방의 가장자리 피부가 큰 충격을 받는 것을 의미하며, 쿠퍼 인대를 강하게 잡아당겨 늘리는 것과 같은 효과를 주므로 쿠퍼 인

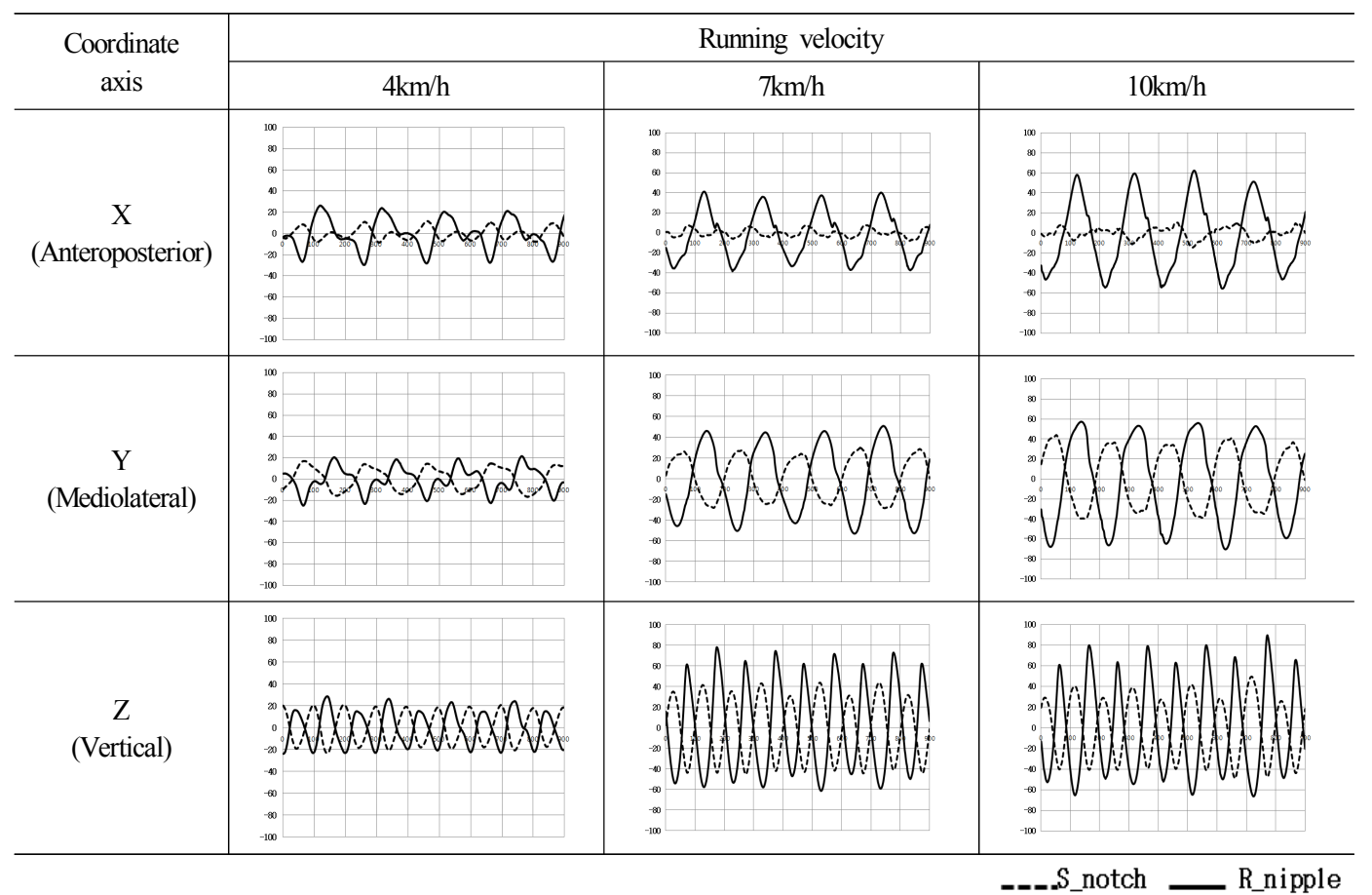

〈Fig. 3〉 Vibration characteristics of the $\mathrm{S}$ _notch and $\mathrm{R}$ nipple by running velocity: subject 1 without bra 
대의 부담을 증가시키고, 유방 조직을 흉곽에 부착 시키는 쿠퍼 인대의 손상을 발생시킬 수 있음을 시 사한다.

유두점 진동 폭을 측정한 결과는 다음과 같다. 워킹 $(4 \mathrm{~km} / \mathrm{h})$ 할 때에는 전후 $(\mathrm{X})$, 좌우 $(\mathrm{Y})$, 상하 $(\mathrm{Z})$ 방향에서 평균 $42.18 \sim 51.11 \mathrm{~cm}$ 의 유사한 진동이 나 타났다. 그러나 조깅 $(7 \mathrm{~km} / \mathrm{h})$ 시에는 전후 $(X)$ 방향 으로는 75.04 82.80mm의 진폭을 나타내었으며, 이 는 워킹 $(4 \mathrm{~km} / \mathrm{h})$ 속도에서의 전후 $(\mathrm{X})$ 방향 진동에 비해 $147 \sim 162 \%$ 증가한 것이었다. 좌우(Y)와 상하 (Z) 방향으로는 더 큰 진폭의 증가를 나타내었다. 좌우(Y) 방향으로는 95.99(227\%) 141.21(330\%)mm, 상하(Z) 방향으로는 $121.58(273 \%) ~ 122.09(289 \%) \mathrm{mm}$ 로 진동하였다. 더 빠른 속도인 스프린팅 $(10 \mathrm{~km} / \mathrm{h})$ 속도의 운동을 실시하였을 때 전후 $(\mathrm{X})$ 방향으로 $110.55(216 \%) 113.90(223 \%) \mathrm{mm}$, 좌우(Y) 방향으로 $121.26(286 \%)$ 166.57(389\%)mm, 상하(Z) 방향으로는 129.06(306\%) 141.22(317\%)mm로 진동하였다(Table 2). 이러한 결과는 빠른 속도로 운동을 할 때 전후, 좌우, 상하 방향에서 유방 진동이 심각하게 증가하 므로, 이를 억제시킬 방안이 필요함을 시사한다. 실험 결과는 피험자 $((\mathrm{n}=2)$ 에 따라 약간의 차이를 나타냈다. 좌우 $(\mathrm{Y})$ 방향 유방 진폭은 피험자 1 은 워 킹 $(4 \mathrm{~km} / \mathrm{h})$ 보다 조깅 $(7 \mathrm{~km} / \mathrm{h})$ 시 2 배가 더 증폭되었으 며, 스프린팅 $(10 \mathrm{~km} / \mathrm{h})$ 시에는 3 배 내외로 유방이 크 게 진동하는 경향을 보였고, 피험자 2 는 조깅 $(7 \mathrm{~km} /$ $\mathrm{h})$ 과 스프린팅 $(10 \mathrm{~km} / \mathrm{h})$ 시 워킹 $(4 \mathrm{~km} / \mathrm{h})$ 에 비해 3 배 이상 진폭이 증가하는 경향을 보였다. 상하(Z) 방 향에서는 두 피험자 모두 조깅 $(7 \mathrm{~km} / \mathrm{h})$ 과 스프린팅 $(10 \mathrm{~km} / \mathrm{h})$ 시 유방의 진동폭이 워킹 $(4 \mathrm{~km} / \mathrm{h})$ 할 때보 다 3 배 내외로 더 크게 유방이 진동하였다. 이 결과 는 젖가슴둘레와 젖가슴아래둘레의 차이로 산출한 컵 치수가 피험자 1 보다 $0.7 \mathrm{~cm}$ 더 큰 피험자 2 가 조깅 $(7 \mathrm{~km} / \mathrm{h})$ 이나 스프린팅 $(10 \mathrm{~km} / \mathrm{h})$ 속도의 운동에 서 좌우(Y) 방향으로 유방이 더 크게 진동함을 보여 준다.

\section{The effect of breast vibration decrease by} sports bra

본 연구에서는 스포츠브라 착용 시 유방 진동 감 소 효과를 상하(Z) 방향의 유두점 진폭만을 중심으 로 수량적인 분석을 실시하였다. 그 이유는 상하(Z) 방향의 진폭이 크며, 진동 빈도수가 전후 $(\mathrm{X})$ 와 좌 우(Y) 방향에 비해 2배 많으므로 운동 시 쿠퍼 인 대 손상에 가장 큰 영향을 줄 수 있기 때문이다. 또 한 Scurr et al.(2011)도 언급했듯이, 유방의 상하 방 향의 진동을 억제시켜 주는 방안을 모색하는 것이 운동 시 유방의 진동으로 인한 유방 통증과 하수 현상 예방에 중요한 요소이기 때문이다.

스포츠브라를 착용한 뒤 나타나는 유방의 진동 파형 변화를 파악하기 위해 브라를 착용하지 않은 상태에서의 유두점 진동 파형과 2종의 스포츠브라

〈Table 2〉 Amplitude of nipple point by speed without bra

(Unit: $\mathrm{mm}$ )

\begin{tabular}{|c|c|c|c|c|}
\hline \multirow{2}{*}{$\begin{array}{l}\text { Coordinate } \\
\text { axis }\end{array}$} & \multirow{2}{*}{ Subject } & \multicolumn{3}{|c|}{ Coordinate value of nipple point } \\
\hline & & $4 \mathrm{~km} / \mathrm{h}$ & $7 \mathrm{~km} / \mathrm{h}$ & $10 \mathrm{~km} / \mathrm{h}$ \\
\hline \multirow{2}{*}{$\begin{array}{c}\mathrm{X} \\
\text { (Anteroposterior) }\end{array}$} & 1 & $\begin{array}{c}51.11 \\
(\mathrm{SD}=3.04,100 \%)\end{array}$ & $\begin{array}{c}75.04 \\
(\mathrm{SD}=3.49,147 \%)\end{array}$ & $\begin{array}{c}110.55 \\
(\mathrm{SD}=6.92,216 \%)\end{array}$ \\
\hline & 2 & $\begin{array}{c}51.02 \\
(\mathrm{SD}=2.45,100 \%)\end{array}$ & $\begin{array}{c}82.80 \\
(\mathrm{SD}=6.60,162 \%)\end{array}$ & $\begin{array}{c}113.90 \\
(\mathrm{SD}=8.35,223 \%)\end{array}$ \\
\hline \multirow{2}{*}{$\begin{array}{c}\text { Y } \\
\text { (Mediolateral) }\end{array}$} & 1 & $\begin{array}{c}42.34 \\
(\mathrm{SD}=2.08,100 \%)\end{array}$ & $\begin{array}{c}95.99 \\
(\mathrm{SD}=6.14,227 \%)\end{array}$ & $\begin{array}{c}121.26 \\
(\mathrm{SD}=6.14,286 \%)\end{array}$ \\
\hline & 2 & $\begin{array}{c}42.79 \\
(\mathrm{SD}=7.26,100 \%)\end{array}$ & $\begin{array}{c}141.21 \\
(\mathrm{SD}=7.84,330 \%)\end{array}$ & $\begin{array}{c}166.57 \\
(\mathrm{SD}=8.68,389 \%)\end{array}$ \\
\hline \multirow{2}{*}{$\begin{array}{c}\mathrm{Z} \\
\text { (Vertical) }\end{array}$} & 1 & $\begin{array}{c}42.18 \\
(\mathrm{SD}=5.91,100 \%)\end{array}$ & $\begin{array}{c}122.09 \\
(\mathrm{SD}=8.66,289 \%)\end{array}$ & $\begin{array}{c}129.06 \\
(\mathrm{SD}=12.59,306 \%)\end{array}$ \\
\hline & 2 & $\begin{array}{c}44.53 \\
(\mathrm{SD}=4.04,100 \%)\end{array}$ & $\begin{array}{c}121.58 \\
(\mathrm{SD}=8.28,273 \%)\end{array}$ & $\begin{array}{c}141.22 \\
(\mathrm{SD}=11.81,317 \%)\end{array}$ \\
\hline
\end{tabular}




\begin{tabular}{|c|c|c|c|c|}
\hline \multirow{2}{*}{ Velocity } & \multirow{2}{*}{ Subjects } & \multicolumn{3}{|c|}{ Bra type } \\
\hline & & No bra & Compression & Encapsulation \\
\hline \multirow{2}{*}{$4 \mathrm{~km} / \mathrm{h}$} & 1 & $\begin{array}{c}42.18 \\
(\mathrm{SD}=5.91,100 \%)\end{array}$ & $\begin{array}{c}6.43 \\
(\mathrm{SD}=1.82,85.0 \%)\end{array}$ & $\begin{array}{c}6.41 \\
(\mathrm{SD}=3.65,84.8 \%)\end{array}$ \\
\hline & 2 & $\begin{array}{c}44.53 \\
(\mathrm{SD}=4.04,100 \%)\end{array}$ & $\begin{array}{c}7.79 \\
(\mathrm{SD}=4.70,82.5 \%)\end{array}$ & $\begin{array}{c}7.26 \\
(\mathrm{SD}=2.74,83.7 \%)\end{array}$ \\
\hline \multirow{2}{*}{$7 \mathrm{~km} / \mathrm{h}$} & 1 & $\begin{array}{c}122.09 \\
(\mathrm{SD}=8.66,100 \%)\end{array}$ & $\begin{array}{c}44.02 \\
(\mathrm{SD}=7.15,63.9 \%)\end{array}$ & $\begin{array}{c}36.91 \\
(\mathrm{SD}=5.63,69.8 \%)\end{array}$ \\
\hline & 2 & $\begin{array}{c}121.58 \\
(\mathrm{SD}=8.28,100 \%)\end{array}$ & $\begin{array}{c}45.43 \\
(\mathrm{SD}=2.90,62.6 \%)\end{array}$ & $\begin{array}{c}39.99 \\
(\mathrm{SD}=4.66,67.1 \%)\end{array}$ \\
\hline \multirow{2}{*}{$10 \mathrm{~km} / \mathrm{h}$} & 1 & $\begin{array}{c}129.06 \\
(\mathrm{SD}=12.59,100 \%)\end{array}$ & $\begin{array}{c}45.02 \\
(\mathrm{SD}=6.82,65.1 \%)\end{array}$ & $\begin{array}{c}40.29 \\
(\mathrm{SD}=9.96,68.8 \%)\end{array}$ \\
\hline & 2 & $\begin{array}{c}141.22 \\
(\mathrm{SD}=11.81,100 \%)\end{array}$ & $\begin{array}{c}51.22 \\
(\mathrm{SD}=4.83,63.7 \%)\end{array}$ & $\begin{array}{c}48.93 \\
(\mathrm{SD}=6.00,65.4 \%)\end{array}$ \\
\hline
\end{tabular}

착용 후 유두점 진동 파형을 비교하였다(Table 3). 분석 결과, 브라를 착용하지 않으면 워킹 $(4 \mathrm{~km} / \mathrm{h})$ 시 에는 유두점이 상하(Z) 방향으로 42.18 44.53mm 진동하였으나, 콤프레션 스포츠브라 착용 시에는 $6.43 \sim 7.79 \mathrm{~mm}$, 인캡슐레이션 스포츠브라 착용 시에 는 $6.41 \sim 7.26 \mathrm{~mm}$ 로 진폭이 $80 \%$ 감소되었다(Table $3)$. 조깅 $(7 \mathrm{~km} / \mathrm{h})$ 시에는 브라를 착용하지 않았을 경 우, 유두점의 진폭이 121.58 122.09mm이었으나, 콤 프레션 스포츠브라나 인캡슐레이션 스타일 스포츠 브라 착용 시 $60 \%$ 이상 진폭이 감소되었다. 빠른 속도로 달리는 스프린팅 $(10 \mathrm{~km} / \mathrm{h})$ 시에도 스포츠브 라를 착용하였을 때 유방 진동이 $60 \%$ 이상 감소하 는 효과를 나타내었다. 2종의 스포츠브라의 스타일 에 따른 유방 진동 억제 효과 차이는 크지 않았다.

\section{Time delay}

러닝 시 발이 지면에 착지하는 과정에서 발생하 는 충격이 유방과 흥곽에 전달되는 매커니즘에서 유방에 미치는 충격의 정도를 파악하기 위하여 앞 목점과 유두점의 진동 파형의 변곡점 중 최고점 발 생 시점의 시간 차이(time delay)를 분석하였다. 분 석결과 앞목점의 높이가 최고점을 향해 상승할 때 유두점은 최저점을 향해 하강하여 상체와 유방이 서로 어긋나는 방향으로 움직이는 경향을 나타내 었다(Fig. 4(a)). 그러나 두 가지 종류의 스포츠브라 를 착용하였을 때에는 앞목점과 유두점 진동 시간 차이가 크게 감소하였다(Fig. 4(b), (c)).

조깅 $(7 \mathrm{~km} / \mathrm{h})$ 시에는 브라를 착용하지 않았을 때 에는 앞목점과 유두점이 $0.24 \sim 0.26$ 초 시간 간격을

$\langle$ Table 4$\rangle$ Comparison of time delay between no bra and experimental sports bra

(Unit: sec)

\begin{tabular}{|c|c|c|c|c|}
\hline \multirow{2}{*}{ Velocity } & \multirow{2}{*}{ Subject } & \multicolumn{3}{|c|}{ Bra type } \\
\hline & & No bra & Compression & Encapsulation \\
\hline \multirow{2}{*}{$7 \mathrm{~km} / \mathrm{h}$} & 1 & $\begin{array}{c}0.24 \\
(\mathrm{SD}=0.01,100 \%)\end{array}$ & $\begin{array}{c}0.06 \\
(\mathrm{SD}=0.01,75.0 \%)\end{array}$ & $\begin{array}{c}0.07 \\
(\mathrm{SD}=0.01,70.8 \%)\end{array}$ \\
\hline & 2 & $\begin{array}{c}0.26 \\
(\mathrm{SD}=0.01,100 \%)\end{array}$ & $\begin{array}{c}0.12 \\
(\mathrm{SD}=0.01,53.8 \%)\end{array}$ & $\begin{array}{c}0.09 \\
(\mathrm{SD}=0.02,65.4 \%)\end{array}$ \\
\hline \multirow{2}{*}{$10 \mathrm{~km} / \mathrm{h}$} & 1 & $\begin{array}{c}0.25 \\
(\mathrm{SD}=0.01,100 \%)\end{array}$ & $\begin{array}{c}0.06 \\
(\mathrm{SD}=0.03,76.0 \%)\end{array}$ & $\begin{array}{c}0.06 \\
(\mathrm{SD}=0.02,76.0 \%)\end{array}$ \\
\hline & 2 & $\begin{array}{c}0.27 \\
(\mathrm{SD}=0.01,100 \%)\end{array}$ & $\begin{array}{c}0.10 \\
(\mathrm{SD}=0.02,63.0 \%)\end{array}$ & $\begin{array}{c}0.08 \\
(\mathrm{SD}=0.03,70.4 \%)\end{array}$ \\
\hline
\end{tabular}


(a) No bra

(b) Compression
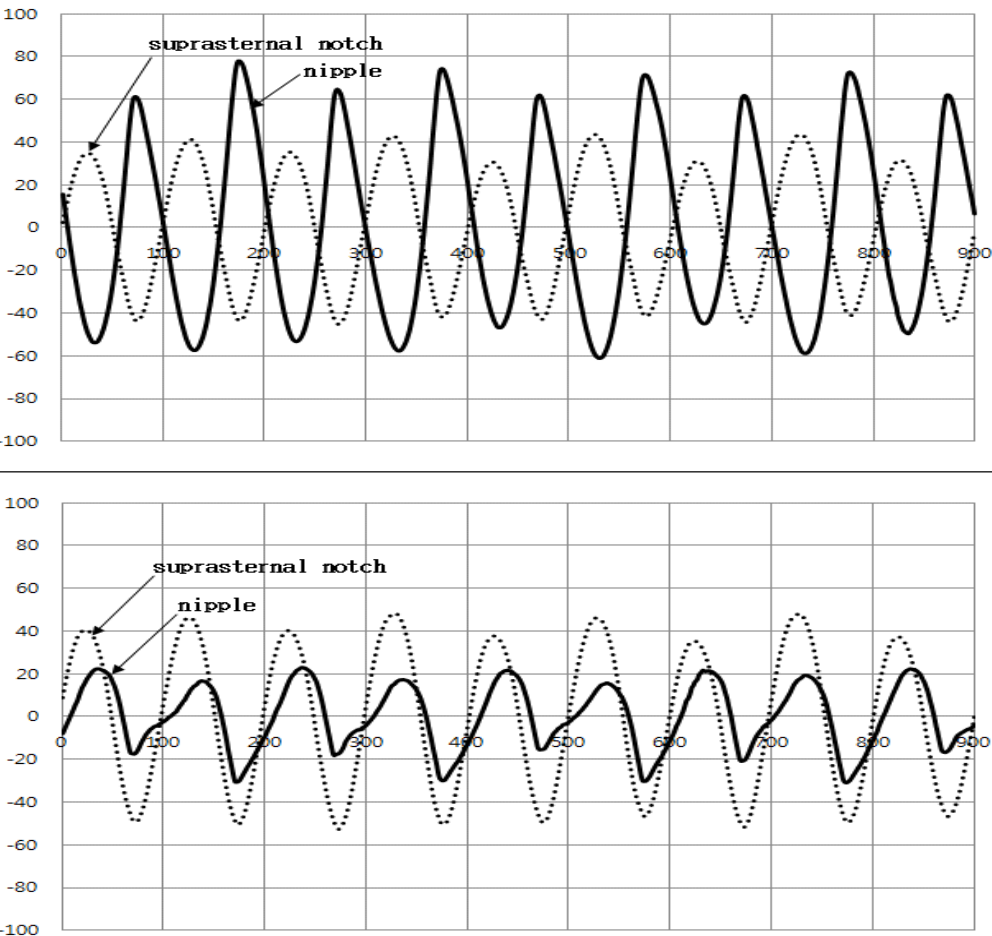

(c) Encapsulation

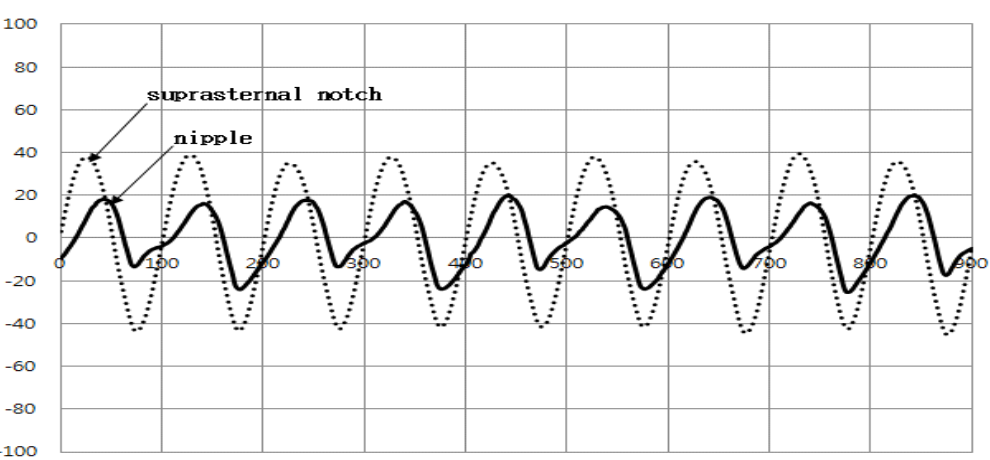

〈Fig. 4〉 Time delay of the S_notch and the nipple(relative to the S_notch) at $7 \mathrm{~km} / \mathrm{h}$ running: subject 1

두고 최고점을 나타내는 진동 파형을 이루었으나, 콤프레션 스포츠브라를 착용하였을 때 0.06 0.12 초, 인캡슐레이션 스포츠브라를 착용하였을 때 0.07 0.09초로 시간 차이가 감소하였다(Table 4, Fig. 4). 스프린팅 $(10 \mathrm{~km} / \mathrm{h})$ 속도로 달리는 조건에서는 브라 를 착용하지 않았을 경우, 0.25 0.27초의 시간 차이 를 나타냈으나, 콤프레션 스포츠브라 착용 시 0.06 0.10 초, 인캡슐레이션 스포츠브라 착용 시 $0.06 \sim 0.08$
초로 감소하였다(Table 4). 피험자별로는 브라를 착 용하지 않은 상태로 운동할 때보다 스포츠브라를 착용하고 운동할 때 시간 차이가 피험자 1 은 70.8 $76.0 \%$ 감소하였고, 피험자 2는 $53.8 ~ 70.4 \%$ 감소하 였다. 이러한 결과는 스포츠브라 착용 시 앞목점과 유두점 파형이 나타나는 시간이 유사해져서 유방 주 변 피부를 당기는 현상이 감소하므로, 쿠퍼 인대가 늘어지는 문제점을 완화시킬 수 있음을 시사한다. 


\section{Conclusion}

유방이 과도하게 진동하는 상태를 방치할 경우, 유방의 형태를 지지해 주는 쿠퍼 인대의 손상이 발 생할 가능성이 크다. 여성들의 스포츠 활동 증가에 따라 쿠퍼 인대 손상을 예방하기 위하여 해외에서 는 운동 시 여성의 유방 진동을 억제시켜 주는 스 포츠브라 제품 개발 연구가 활발하게 이루어지고 있다. 이러한 기능성 의류제품의 착용 효과는 스포 츠과학 분야의 기초 연구 데이터를 이용하여 입증 할 수 있다(Chun \& Jee, 2011). 그러나 이는 여성의 민감한 신체 조직인 유방을 대상으로 연구가 이루 어져야 하므로, 국내에서는 여성의 유방 진동 특성 에 대한 데이터 수집과 분석 연구가 거의 이루어지 지 않고 있다. 따라서 본 연구는 소수이지만 한국 여성을 대상으로 러닝 시 유방의 진동 특성을 분석 하고, 스포츠브라 착용에 따른 유방 진동 감소 효 과를 검증하였다.

최근 국내 여성들의 유방 사이즈가 증가하는 추 세를 반영하여 본 연구에서는 $\mathrm{C}$ 컵에 해당하는 20 대 여성 $(\mathrm{n}=2)$ 을 대상으로 브라를 착용하지 않은 상 태와 콤프레션 스타일과 인캡슐레이션 스타일의 스 포츠브라를 착용한 후 일정한 속도로 움직이는 조 건이 형성되는 트레드밀에서 걷거나 달리는 상태 에서 유두점의 상하 방향 진동 폭과 진동 파형을 비교 분석하고, 앞목점과 유두점의 진동 파형 발생 시간 차이를 측정하여 운동 시 유방이 받게 되는 충격을 정량화하여 비교하였다. 연구 결과, 다음과 같은 결론을 도출하였다.

첫째, 브라를 착용하지 않은 상태에서 러닝할 경 우, 유방은 전후보다는 좌우와 상하 방향으로 더 크 게 진동하였다. 또한 조깅 $(7 \mathrm{~km} / \mathrm{h})$ 시에는 워킹 $(4 \mathrm{~km} / \mathrm{h})$ 상태 때보다 $270 \%$ 이상, 스프린팅 $(10 \mathrm{~km} / \mathrm{h})$ 시에는 $300 \%$ 이상 유방의 상하 진동 폭이 증가하였다. 이러 한 본 연구의 결과는 유방의 진동을 억제할 수 있는 브라를 착용하지 않는 상태에서 운동할 경우 조깅 $(7 \mathrm{~km} / \mathrm{h})$ 정도의 속도에서도 유방의 쿠퍼인대 손상이 크게 발생할 수 있는 가능성이 있음을 시사한다.

둘째, 본 연구의 실험 참가자들은 동일한 브라컵 에 해당하였으나 이중 유방 사이즈가 약간 더 큰 피험자(2)의 유방이 상대적으로 약간 더 작은 피험
자(1)보다 좌우(Y) 방향으로 더 크게 진동하는 경 향을 나타내었다. 이와 같은 결과는 후속연구에서 유방의 처짐 정도나 크기에 따른 유방 진동의 특성 을 파악할 필요가 있음을 시사한다. 특히 정확한 원인을 파악하기 위해서는 유방의 해부학적 특성 및 역학적인 특성 측면의 후속 연구를 통해 유방 크기 및 형태적인 차이가 러닝 시 유방 진동에 어 떤 영향을 줄 수 있는지를 규명할 필요가 있다.

셋째, 스포츠브라 착용에 따른 유방 진동 감소 효과는 모든 속도에서 나타났다. 워킹 $(4 \mathrm{~km} / \mathrm{h})$ 시에 는 $80 \%$ 이상 감소하였고, 조깅 $(7 \mathrm{~km} / \mathrm{h})$ 과 스프린팅 $(10 \mathrm{~km} / \mathrm{h})$ 시에는 $60 \%$ 이상 감소하였다.

넷째, 러닝 시 앞목점과 유두점 진동 파형 진행 시간 차이를 측정하여 러닝 시 유방이 받게 되는 충격을 정량적으로 분석한 결과, 스포츠브라를 착 용하지 않았을 때에는 상체가 하강할 때 유방은 상 승하여 상체와 유방이 서로 반대되는 방향으로 움 직이므로, 유방의 주변 피부와 쿠퍼 인대의 큰 부담 을 주는 것으로 나타났다. 그러나 스포츠브라를 착 용한 상태에서는 상체가 상승할 때 유방도 같이 상 승하는 경향을 나타내었다. 이러한 결과는 스포츠 브라를 착용하고 운동을 하면 유방을 상체에 밀착 시켜 유방과 상체가 함께 움직이도록 하여 유방이 받게 되는 충격을 감소시켜 유방의 쿠퍼인대 손상 을 예방할 수 있음을 시사한다.

본 연구는 유방이 큰 한국 여성을 대상으로 스포 츠브라 착용에 따른 여성의 유방 진동 감소 효과를 정량적으로 분석하여 스포츠브라의 착용 필요성을 입증하였다는데 의의가 있다.

여성의 유방이라는 민감한 부위를 대상으로 하 여 연구가 이루어진 관계로 제한된 피험자를 대상 으로 하여 피험자수가 적다는 제한점이 있으나, 선 행연구에서도 피험자 1 인의 자료를 바탕으로 연구 가 이루어졌다. 이는 본 연구의 연구 방법이 유방 의 진동을 명확하게 규명할 수는 있으나, 피험자의 수치심을 일으킬 수 있는 방법이므로, 피험자 확보 가 어렵다는 한계를 가지고 있기 때문이다. 후속 연구에서는 국내 여성의 상당수를 차지하는 $\mathrm{A}$ 컵과 $\mathrm{B}$ 컵 사이즈의 여성들을 대상으로 자료를 수집하여 분석할 필요가 있다.

마지막으로 본 연구에서는 상하 방향의 유두점 
진폭에 대해서만 분석하였고, 전후, 좌우 움직임 진 폭 분석은 배제하였다. 따라서 후속 연구에서는 여 성들의 유방 움직임이 전후, 좌우로 많이 움직이는 골프 및 스쿼시에서 발생하는 유방의 진동범위에 대한 검증이 이루어진다면 여성들의 운동 종목에 따른 적합한 스포츠브라의 개발 및 디자인 제언이 가능할 것으로 기대된다.

\section{References}

Bridgman, C., Scurr, J. C., White, J. Hedger, W., \& Galbraith, H.(2010). Three-dimensional kinematics of the breast during a two-step star jump. Journal of Applied Biomechanics, 26(4), 465-472.

Chang, L. X., Gao, W. D., \& Yan, X. L.(2009). Studies of sports bra based on biomorphic analysis of females breasts. Bioinformatics and Biomedical Engineering. ICBBE 3rd International Conference on Jiangnan University, Wuxi, China.

Cho, S. H., \& Kim, M. S.(2008). Brassiere pattern development based on 3D measurements of upper body: Focused on women in their 30's. The Research Journal of the Costume Culture, 16(3), 488-501.

Chun, J., \& Jee, J. W.(2011, November). Ergonomic functional clothing design trends. Annual Research Seminar of The Costume Culture Association(CCA). Seoul, Korea.

Gefen, A., \& Dilmoney, B.(2007). Mechanics of the normal woman's breast. Technology and Health Care, 15, 259-271.

Grassley, J. S.(2002). Breast reduction surgery: What every women needs to know. Lifelines, 6, 244-249.

Haake, S., \& Scurr, J. C.(2010). A dynamic model of the breast during exercise. Sports Engineering, 12, 189-197.

Jang, Y. M., Chun, J., Lee, H. D., \& Han, B. R.(2013). A study on the design features for sports bra styles according to treadmill running speeds and bra cup sizes. The Research Journal of the Costume Culture, 21(1), 81-92.
Kim, N. S.(2008). Classification of upper body types from the $3 \mathrm{D}$ body scan data and pattern design of the big size brassiere using clothes modeling system: Focused on more than C cup size. Unpublished master's thesis, Chonnam University, Gwangju, Korea.

Ko, B. S.(2013, May 2). The breast of Korea women has become much bigger. Naeil. Retrieved March 5, 2014, from http://news.naver.com

Ko, J. S., Kim, S. O., Kim, W. S., Kim, J. B., Kim, J. K., Park, K. H., Pack, S. Y., Ahn, E. T., \& Yang, Y. C.(2000). Human anatomy. Seoul: Jungmunkag. Page, K. A., \& Steele, J. R.(1999). Breast motion and sports brassiere design: Implications for future research. Sports Medicine, 27(4), 205-211.

Rigal, J. D., Escoffier, C., Querleux, B., Faivre, B., Agache, P., \& Leveque, J. L.(1989). Assessment of aging of the human skin by in vio ultrasonic imaging. Journal of Investigative Dermatology, 93, 621-625.

Scurr, J. C., White, J. L., \& Hedger, W.(2011). Supported and unsupported breast displacement in three dimensions across treadmill activity levels. Journal of Sports Sciences, 29(1), 55-61.

Scurr, J. C., White, J. L., \& Hedger, W.(2010). The effect of breast support on kinematics of the breast during the running gait cycle. Journal of Sports Sciences, 28(10), 1103-1109.

Starr, C.(2005). Biomechanical analysis of a prototype sports bra. Journal of Textile and Apparel, 4(3), $1-14$.

White, J. L., Scurr, J. C., \& Smith, N. A.(2009). The effect of breast support on kinetics during overground running performance. Ergonomics, 52(4), 492-498.

Woo, S. L., Ambramouwitch, S. D., Kilger, R., \& Lianf, R.(2003). Biomechanics of knee ligaments: injury, healing, and repair. Journal of Biomechanics, 39, 1-20. 